\title{
Fingertip replantation (zone I) without venous anastomosis: clinical experience and outcome analysis
}

\author{
An-shi Huan ${ }^{1,2 \dagger}$, Subhash Regmi ${ }^{2 \dagger}$, Jia-xiang Gu${ }^{1 *}$, Hong-jun Liu ${ }^{1}$ and Wen-zhong Zhang ${ }^{1}$
}

\begin{abstract}
Purpose: The purpose of this study was to report our experience of fingertip replantation without venous anastomosis using alternate method to counter post-operative venous congestion.

Methods: 30 Patients ( 18 men and 12 women) with 30 fingertip amputations (Tamai zone I) were treated with artery-only anastomosis fingertip replantation between March 2010 and July 2014. Postoperative venous outflow was maintained by allowing bleeding through wound gaps combined with topical (12500 $: 250 \mathrm{mINS})$ and systemic (4000 IU SC once daily) heparin. The outcomes of replantation were evaluated using standard evaluating systems.

Results: The average duration of hospital stay was 10 days (range 7-14 days). Twenty-eight (93\%) replanted fingertips survived. Five replanted fingertip experienced postoperative vascular crisis. The estimated post-operative blood loss was about 200-450 ml (mean, $292 \mathrm{ml}$ ). Follow-up period ranged from 12 to 24 months (average, 18 months). At final follow-up examinations, the average value of static two point discrimination test was $5.6 \mathrm{~mm}$ (range 3-9 mm) and Semmes-Weinstein monofilament test was $3.35 \mathrm{~g}$ (range 2.83-4.56 g). The mean range of motion of distal interphalangeal joint was $65.2^{\circ}$ (range $0-90^{\circ}$ ) and all patients returned to their work within 7-18 weeks (average, 11 weeks).

Conclusion: Artery-only fingertip replantation can provide satisfactory cosmetic and functional results. Adequate venous outflow can be obtained by allowing minimal external bleeding through wound gaps combined with topical and systemic heparin.
\end{abstract}

Keywords: Fingertip amputation, Tamai zone I, Artery-only anastomosis, Replantation

\section{Background}

Tamai (1982) zone I (distal to the nail base) replantation possess considerable challenge to hand surgeons, because venous anastomosis is extremely difficult, and venous congestion is a leading cause of failure (Barbary et al. 2013; Hattori et al. 2003). Despite having some limitations, artery-only replantation for zone I amputations has gained popularity over the years (Han et al. 2002; Streit et al. 2014; Kim et al. 2014; Whitaker et al. 2012;

\footnotetext{
*Correspondence: gujiaxiang69@gmail.com; gjx69@163.com

${ }^{\dagger}$ An-shi Huan and Subhash Regmi contributed equally to this work

1 Department of Hand and Foot Surgery, Subei People's Hospital, Clinical Medical College of Yangzhou University, Yangzhou City 225001, Jiangsu Province, People's Republic of China

Full list of author information is available at the end of the article
}

Chen et al. 2013, 2014; Jeon et al. 2016; Matsuda et al. 1993). Many authors have described various techniques, including external bleeding protocol using pulpar incision (Hasuo et al. 2009), partial nail plate removal (Yabe et al. 2001), and paraungual area stab incision (Gordon et al. 1985) and application of medicinal leech (Han et al. 2002) and mechanical leech (Streit et al. 2014) to counter venous congestion. However, none has provided entirely satisfactory results.

Therefore, in this study, we report our experience of 30 artery-only fingertip replantations and describe an alternative technique to manage postoperative venous congestion. In addition, we rigorously evaluate the outcomes of replantation using standard evaluating systems. 


\section{Patients and methods}

We reviewed clinical data records of patients who underwent fingertip replantation in our hospital. Patients with Tamai zone I replantations were included for the study. For each included patients, the following data were recorded: age, sex, mechanism of injury, location of the amputation, ischemia time, operation time, estimated post-operative blood loss, complications and duration of hospital stay and follow-up.

This study was approved by local ethical committee of Subei People's Hospital and institutional review board of Yangzhou University.

\section{Surgical procedure}

Preoperatively, patients were explained thoroughly about the risks and benefits of the procedure and written informed consents (for both the procedure and inclusion in the study) were obtained. Operation was done under digital nerve block anesthesia with rubber tourniquet (applied at the base of the finger) control.

Under surgical microscope $(25 \times$ magnification), the debridement of the distal amputated stump and proximal stump was done to isolate vessels and nerves for anastomosis. Fracture fixation was done with K-wire using retrograde trans-fixation method in all cases. Arterial anastomosis was done in an end-to-end fashion in all the cases using non-absorbable microscopic sutures (10-0 or 11-0 prolene sutures). Of 30 fingertip replantations, 24 underwent one artery anastomosis and 6 underwent two artery anastomoses. Venous anastomosis was not possible in all cases. Nerve repair was done in 16 fingers. The nail bed was repaired carefully, using 5-0 absorbable sutures. The skin was loosely sutured using 4-0 prolene sutures, four to six stitches were applied at about $1 \mathrm{~cm}$ apart.

\section{Postoperative regime}

All patients were treated with intravenous papaverine $(30 \mathrm{mg}$ every $8 \mathrm{~h}$ ) and subcutaneous heparin (4000 IU once-daily) injections for 2-4 days. Postoperative bleeding was allowed for 12-24 h through wound gaps, and the area was frequently washed with heparinized normal saline solution $\left(12500^{\mathrm{u}}: 250 \mathrm{ml}\right)$. Replanted fingertips were frequently monitored for vascular crisis and evidences of venous congestion. Patients were kept under controlled temperature of $20-25^{\circ} \mathrm{C}$.

\section{Follow up outcome evaluation}

Patients were followed up regularly. At final followup visit, the sensibility outcomes were evaluated using static two point discrimination (s2PD) (using calipers) and Semmes-Weinstein monofilament (SWM) tests (using monofilaments of size 2.83, 3.61 and $4.56 \mathrm{~g}$ ). In addition, range of motion of DIP joints (degrees) and return-to-work time (weeks) were noted. All the examinations were done by surgeon who was not the part of initial treatment process.

\section{Results}

We enrolled 30 patients (18 men and 12 women), who underwent artery-only fingertip replantation between March 2010 and July 2014. The average age was 34 years (range 19-52 years). The mechanisms of injury were clean-cut injury (13 patients), crush-cut injury (13 patients) and crush-avulsion injury (4 patients). Right hand and left hand ratio was 1:1. The digits involved were thumbs ( 2 patients), index fingers (10 patients), long fingers (10 patients), ring fingers (6 patients) and little fingers ( 2 patients). All fingertip amputations were Tamai zone I amputations. The mean ischemia time was $3.4 \mathrm{~h}$ (range $1.6-5 \mathrm{~h}$ ). The mean operation time was $2.4 \mathrm{~h}$ (range 1.8-3.3 h) (Table 1).

The average duration of hospital stay was 10 days (range 7-14 days). Twenty-eight (93\%) replanted fingertips survived. Five replanted fingertip experienced postoperative vascular crisis, three of them survived after thrombectomy and re-anastomosis. The estimated post-operative blood loss was about 200-450 ml (mean, $292 \mathrm{ml}$ ). All patients with survived fingertip were available for followup. Follow-up period ranged from 12 to 24 months (average, 18 months). At final follow-up examinations, the average value of static two point discrimination (2PD) test was $5.6 \mathrm{~mm}$ (range 3-9 $\mathrm{mm}$ ) and Semmes-Weinstein monofilament (SWM) test was $3.35 \mathrm{~g}$ (range 2.83-4.56 g). The mean range of motion (ROM) of distal interphalangeal joint (DIPJ) was $65.2^{\circ}$ (range $0-90^{\circ}$ ) and all patients returned to their work within 7-18 weeks (average, 11 weeks) (Table 2).

Complications include complete necrosis (7\%), postoperative vascular crisis (17\%), pulp atrophy (20\%), mild-to-moderate cold intolerance (20\%), nail deformity (20\%), bony mal-union (17\%), joint stiffness (10\%), and neuroma formation (7 \%) (Table 3).

\section{Discussion}

Fingertip amputations are very common in developing world. There are varieties of treatment options available, such as replantation, revision amputation, composite grafts, local flaps, and free tissue transfer (Barbary et al. 2013; Peterson et al. 2014). However, the ideal reconstruction must restore digital length and provide adequate sensation and satisfactory range of motion (Peterson et al. 2014). Therefore, successful replantation is always superior to any other methods of reconstruction (Yabe et al. 2012).

Despite being an ideal choice of reconstruction, fingertip replantation is not commonly performed because 
Table 1 Demographic data (31 patients with 31 fingertip amputations)

\begin{tabular}{|c|c|c|c|c|c|c|c|c|c|}
\hline Cases & $\begin{array}{l}\text { Age (years)/ } \\
\text { sex }\end{array}$ & $\begin{array}{l}\text { Mechanism } \\
\text { of injury }\end{array}$ & $\begin{array}{l}\text { Injured } \\
\text { finger }\end{array}$ & $\begin{array}{l}\text { Ischemia } \\
\text { time (h) }\end{array}$ & $\begin{array}{l}\text { Operation } \\
\text { time (h) }\end{array}$ & $\begin{array}{l}\text { Estimated } \\
\text { blood loss } \\
(\mathrm{ml})\end{array}$ & $\begin{array}{l}\text { Duration } \\
\text { of hospital } \\
\text { stay (days) }\end{array}$ & $\begin{array}{l}\text { Number } \\
\text { of arterial } \\
\text { anastomosis }\end{array}$ & Outcome \\
\hline 1 & 20/F & Crush-cut & Left thumb & 3.5 & 2.4 & 240 & 8 & 1 & Survived \\
\hline 2 & $23 / \mathrm{M}$ & Cut & Right index & 2 & 2 & 400 & 9 & 1 & Survived \\
\hline 3 & $32 / M$ & Cut & Left ring & 2.5 & 1.8 & 300 & 12 & 1 & Survived \\
\hline 4 & $47 / M$ & Crush-cut & Right index & 2.2 & 2.7 & 240 & 9 & 1 & Survived \\
\hline 5 & $18 / \mathrm{M}$ & Crush-Avulsion & Left Long & 5 & 3.3 & 250 & 7 & 1 & Failed \\
\hline 6 & $32 / F$ & Cut & Left index & 3.7 & 1.5 & 220 & 8 & 2 & Survived \\
\hline 7 & $41 / F$ & Crush-cut & Right ring & 2.5 & 2.2 & 300 & 10 & 1 & Survived \\
\hline 8 & $36 / M$ & Crush-cut & Left long & 2.2 & 3.1 & 350 & 10 & 1 & Survived \\
\hline 9 & $41 / \mathrm{M}$ & Cut & Right ring & 2.7 & 2.5 & 300 & 9 & 1 & Survived \\
\hline 10 & $45 / M$ & Cut & Left index & 1.6 & 2.3 & 450 & 10 & 1 & Survived \\
\hline 11 & $39 / F$ & Crush-cut & Right ring & 2.3 & 2.7 & 250 & 10 & 1 & Survived \\
\hline 12 & $28 / M$ & Crush-cut & Left long & 4.1 & 2.5 & 250 & 12 & 1 & Survived \\
\hline 13 & $47 / F$ & Crush-cut & Left little & 2.7 & 3.3 & 280 & 8 & 1 & Survived \\
\hline 14 & $35 / F$ & Crush-cut & Right ring & 3.3 & 2.7 & 200 & 9 & 1 & Survived \\
\hline 15 & $34 / F$ & Cut & Right index & 3.5 & 2 & 320 & 9 & 2 & Survived \\
\hline 16 & $25 / M$ & Cut & Left Long & 4.5 & 2.1 & 220 & 8 & 2 & Survived \\
\hline 17 & $52 / \mathrm{M}$ & Cut & Right index & 3.7 & 2.6 & 200 & 10 & 1 & Survived \\
\hline 18 & $30 / M$ & Crush-cut & Right long & 3.9 & 2.3 & 350 & 7 & 1 & Failed \\
\hline 19 & $26 / M$ & Crush-Avulsion & Left ring & 4.5 & 2.5 & 200 & 10 & 1 & Survived \\
\hline 20 & $25 / F$ & Crush-cut & Right long & 3.2 & 2.7 & 220 & 8 & 1 & Survived \\
\hline 21 & $34 / M$ & Crush-cut & Right index & 4.6 & 2.3 & 340 & 10 & 1 & Survived \\
\hline 22 & 19/M & Cut & Left Long & 3.5 & 2.2 & 300 & 12 & 2 & Survived \\
\hline 23 & $25 / M$ & Crush-cut & Left index & 4.3 & 2.7 & 450 & 14 & 1 & Survived \\
\hline 24 & $28 / M$ & Crush-Avulsion & Right little & 3.7 & 3 & 250 & 8 & 1 & Survived \\
\hline 25 & $44 / F$ & Cut & Right long & 3.5 & 1.9 & 320 & 10 & 2 & Survived \\
\hline 26 & $37 / M$ & Crush-Avulsion & Left long & 4.5 & 3.2 & 350 & 7 & 1 & Survived \\
\hline 27 & $43 / F$ & Cut & Right long & 2.6 & 2.1 & 280 & 9 & 2 & Survived \\
\hline 28 & $42 / F$ & Crush-cut & Left index & 3.5 & 2.3 & 240 & 9 & 1 & Survived \\
\hline 29 & $34 / M$ & Cut & Right index & 3.5 & 1.8 & 280 & 8 & 1 & Survived \\
\hline 30 & $25 / F$ & Cut & Left thumb & 3.4 & 2 & 420 & 9 & 1 & Survived \\
\hline Mean & 33.6 & & & 3.4 & 2.4 & 292.3 & 9.3 & & \\
\hline
\end{tabular}

$M$ male, $F$ female

of some inherent difficulties, including identification of blood vessel, small vessel anastomosis and post-operative venous congestion (Kim et al. 2013). In our study, we used a different method to fix the amputated stump during debridement to facilitate the identification process (Fig. 1). This method allows better access and avoids further (iatrogenic) damage to neurovascular structures. Micro-vascular anastomosis has become easier these days with the availability of surgical microscopes $(25 \times$ magnifications). However, extreme care should be taken during the procedure to avoid endothelial injury, which is the main cause for post-operative vascular crisis (Figs. 2, $3,4,5)$.
Venous congestion after artery-only fingertip replantation (zone I) is an inevitable phenomenon (Hattori et al. 2003). If not addressed early, it becomes problematic and may cause failure (Buntic and Brooks 2010; Venkatramani and Sabapathy 2011). Adequate restoration of venous outflow is required to obtain success. Various techniques, such as pulpar incision, partial nail plate removal, and paraungual area stab incision have been used to allow post-operative bleeding to maintain adequate venous outflow (Hasuo et al. 2009; Yabe et al. 2001; Gordon et al. 1985). In addition, some other techniques, such as application medicinal leech and mechanical leech have also been used (Han et al. 2002; Streit et al. 2014). These 
Table 2 Follow-up evaluation

\begin{tabular}{lllllc}
\hline Case & $\begin{array}{l}\text { Follow-up } \\
\text { (months) }\end{array}$ & 2PD (mm) & SWM (g) & $\begin{array}{l}\text { ROM } \\
\text { of DIPJ }\left(^{\circ}\right)\end{array}$ & RTW (week) \\
\hline 1 & 12 & 5 & 2.83 & 80 & 12 \\
2 & 12 & 7 & 3.61 & 60 & 13 \\
3 & 18 & 5 & 2.83 & 82 & 12 \\
4 & 18 & 5 & 2.83 & 80 & 10 \\
5 & 12 & 6 & 3.61 & 65 & 12 \\
6 & 18 & 5 & 2.83 & 80 & 8 \\
7 & 12 & 7 & 3.61 & 70 & 9 \\
8 & 18 & 5 & 2.83 & 74 & 8 \\
9 & 24 & 4 & 2.83 & 82 & 12 \\
10 & 24 & 3 & 2.83 & 90 & 12 \\
11 & 12 & 6 & 3.61 & 66 & 8 \\
12 & 24 & 3 & 2.83 & 90 & 10 \\
13 & 12 & 6 & 3.61 & 55 & 10 \\
14 & 18 & 5 & 3.61 & 72 & 12 \\
15 & 18 & 6 & 3.61 & 70 & 10 \\
16 & 12 & 9 & 4.56 & 0 & 16 \\
17 & 15 & 8 & 4.56 & 0 & 18 \\
18 & 18 & 6 & 3.61 & 40 & 10 \\
19 & 18 & 6 & 3.61 & 70 & 8 \\
20 & 18 & 5 & 2.83 & 68 & 7 \\
21 & 24 & 4 & 2.83 & 90 & 12 \\
22 & 12 & 7 & 3.61 & 40 & 12 \\
23 & 24 & 4 & 2.83 & 90 & 8 \\
24 & 18 & 9 & 4.56 & 0 & 14 \\
25 & 18 & 7 & 3.61 & 60 & 11 \\
26 & 24 & 3 & 2.83 & 90 & 8 \\
27 & 24 & 4 & 2.83 & 90 & 9 \\
28 & 18 & 6 & 3.61 & 72 & 10 \\
Mean & 17.7 & 5.6 & 3.35 & 65.2 & 10.8 \\
\hline $2 P D$ & 50 & 5012 & \\
\hline
\end{tabular}

$2 P D$ two point discrimination test, SWM Semmes-Weinstein monofilament test, $R O M$ of DIPJ ( $\left(^{\circ}\right)$ range of motion of distal interphalangeal joint, RTW Return time to work

\section{Table 3 Prevalence of complications}

\begin{tabular}{ll}
\hline Complications & Number of cases \\
\hline 1. Complete necrosis & $2(7 \%)$ \\
2. Vascular crisis & $5(17 \%)$ \\
3. Mild to moderate cold intolerence & $6(20 \%)$ \\
4. Pulp atrophy & $6(20 \%)$ \\
5. Joint stiffness & $3(10 \%)$ \\
6. Bony mal-union & $5(17 \%)$ \\
7. Nail deformitiy & $6(20 \%)$ \\
8. Neuroma formation & $2(7 \%)$ \\
\hline
\end{tabular}

techniques have been extremely successful. However, bleeding is often very profound and may require blood transfusion. Erken et al. (2013) reported controlled nail

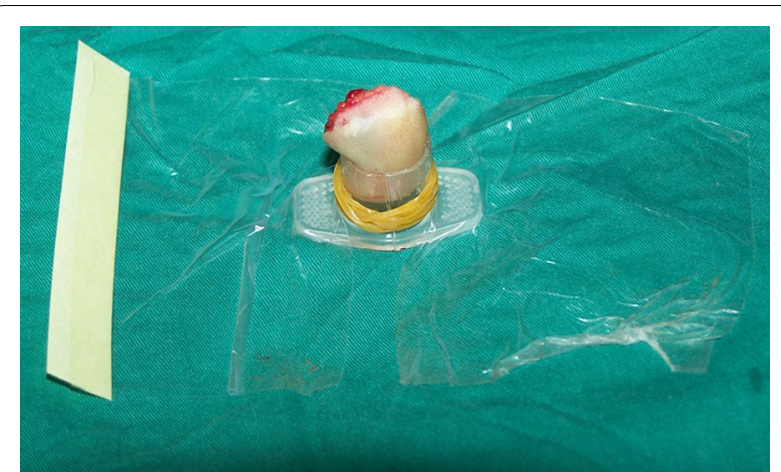

Fig. 1 1/5th portion of the 5 cc syringe barrel was split from one side and the amputated part of finger tip was placed inside (injured portion facing upward). The elastic rubber band was used to wrap the barrel and fix the amputated part. The amputated part of fingertip along with the syringe barrel was dipped into disinfectant solution and then placed on surgical table

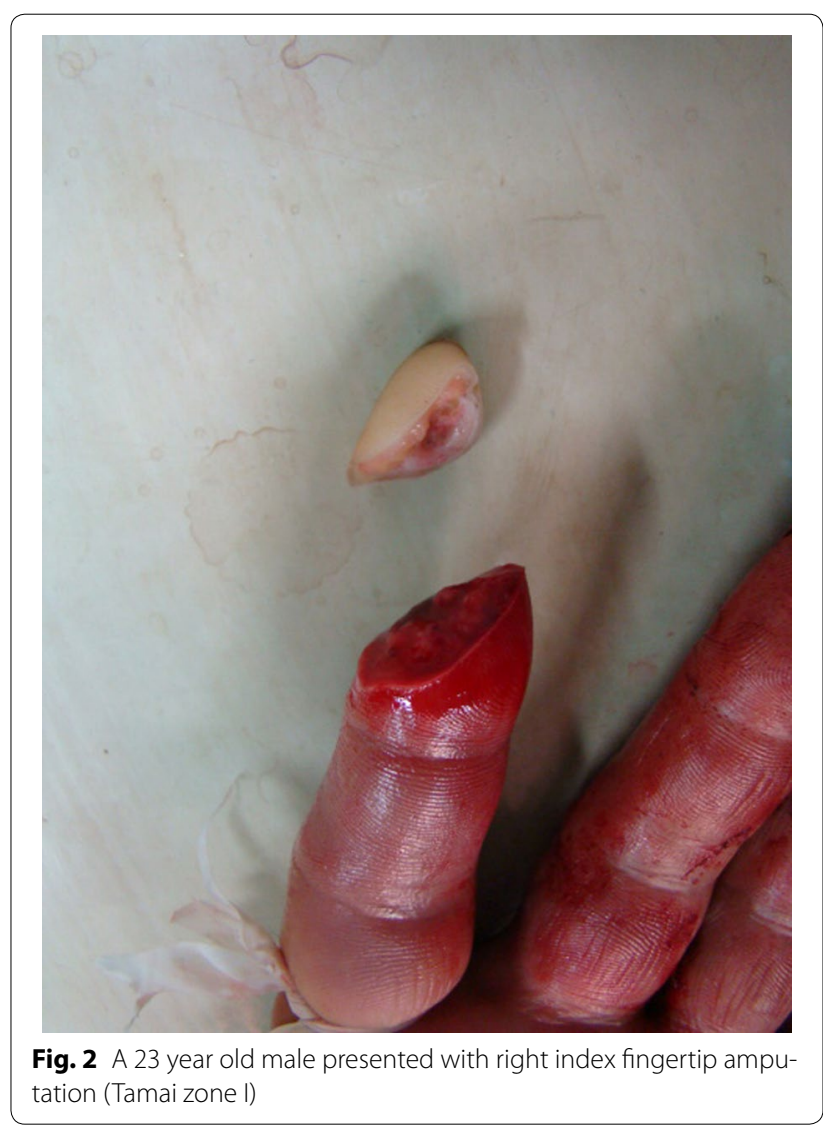

bed bleeding protocol for artery-only fingertip replantation and 15 of 22 patients required blood transfusion.

Arteriovenous (AV) shunting is another alternative to restore adequate venous drainage (Nichter et al. 1985; Chen et al. 2005). This technique is commonly performed as a salvage procedure for arterial inflow or venous 


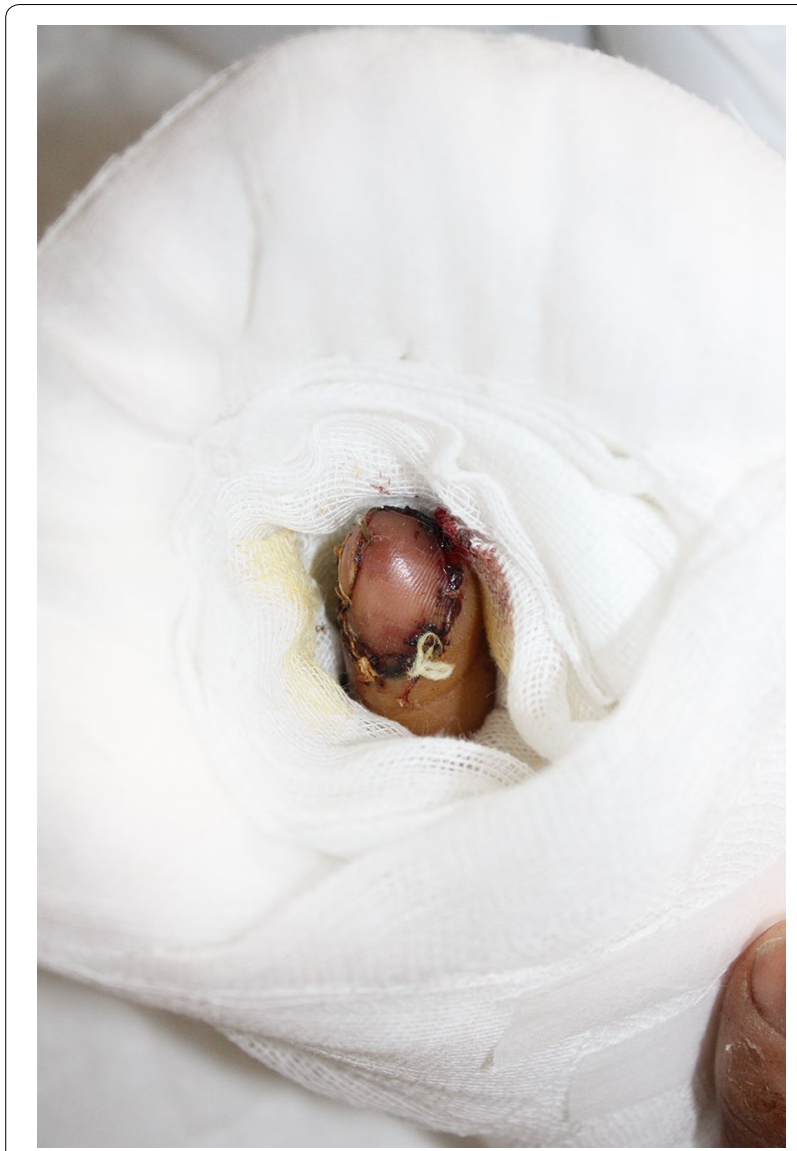

Fig. 3 Fingertip replantation was done using artery-only anastomosis technique. Postoperative bleeding was allowed through the wound gaps

drainage when the standard artery-to-artery or veinto-vein anastomoses become impossible. Nitcher et al. (1985) performed an experimental study which strongly supports efferent AV shunting (single arterial inflow with efferent AV fistula for venous outflow) technique in the management of replants with absent venous drainage. However, this technique requires patent venous structures at the amputated stump. In addition, literature lacks enough evidence to support the usage of this technique (efferent AV shunting) to restore venous outflow in artery-only fingertip replantation. Peterson et al. (2014), in their recent study, have concluded that artery-only fingertip replantation (zone I) may not require obligatory external bleeding to restore venous outflow. We also support his findings and agree to the fact that venous outflow could be managed by the bleeding that occurred from wound-edge and bone marrow reflux (Tanaka et al. 1998; Chen et al. 1991). Therefore, in our study we sutured skin loosely and allowed post-operative bleeding through the suture gaps. We applied heparinized normal saline solution $\left(12500^{\mathrm{u}}: 250 \mathrm{ml}\right)$ topically to avoid obstruction due to clot formation. We observed minimal oozing of blood for about 12-24 h. Mild venous congestion was observed in all patients, which resolved in 2-4 days. Fingertip temperature and blood color on pinprick were used as the indicators to determine successful replantation. Total estimated post-operative blood loss was about $200-450 \mathrm{ml}$ and no blood transfusion was required.

Despite having successful results, we do not recommend intended artery-only anastomosis in Tamai zone I replantations. Surgeons should make every effort to carefully isolate the vein and perform venous anastomosis. In our study, we were able to isolate veins only in patients who presented with clean-cut amputations. However, those veins were not suitable for anastomosis. In addition, we performed two arterial anastomoses in 6 patients and found that venous congestion subsided early ( 2 days) in those patients. This proves the fact that better post-operative perfusion decreases the duration of venous congestion and improves the survival (Matsuda et al. 1993).

In our study, postoperative vascular crisis was observed in 5 replanted fingertips. Three replanted fingertip survived after thrombectomy and re-anastomosis whereas ischaemic necrosis occurred in two cases. Patients with survived fingertips $(n=28)$ were included for final follow-up evaluation. According to the results, sensibility outcomes (mean s2PD $=5.6 \mathrm{~mm}$ and SWM $=3.35 \mathrm{~g}$ ) were satisfactory. The sensibility outcomes tend to improve with time (at 24 month follow up, s2PD $=3 \mathrm{~mm}$ ). There was no significant difference ( $\mathrm{P}=0.35, \alpha=0.05$, using ANOVA) in s2PD outcomes between patients with nerve anastomosis (mean \pm S.D. $=5.5 \pm 1.78 \mathrm{~mm}, \mathrm{n}=16$ ) and without nerve anastomosis (mean \pm S.D. $=6.07 \pm 1.49 \mathrm{~mm}$, $\mathrm{n}=14$ ). Our outcomes could not deny the fact that fingertip replantation can provide satisfactory sensory recovery without nerve anastomosis (Ozcelik et al. 2008). However, some complications, such as pulp atrophy and neuroma formation were found in patients in whom nerve anastomosis were not performed. Therefore, we believe the importance of nerve anastomosis should not be neglected and surgeons should perform nerve repair whenever possible.

In our study, the ROM of DIPJ was satisfactory and all patients returned to their normal work. Our results were better compared to that reported in the literature (Sebastin and Chung 2011). However, there were some associated complications, such as cold intolerance, pulp atrophy, bony malunion, joint stiffness, and neuroma formation.

Our results showed that fingertip replantation is superior to any other method of reconstruction for the treatment of fingertip amputation. However, the reliability of 


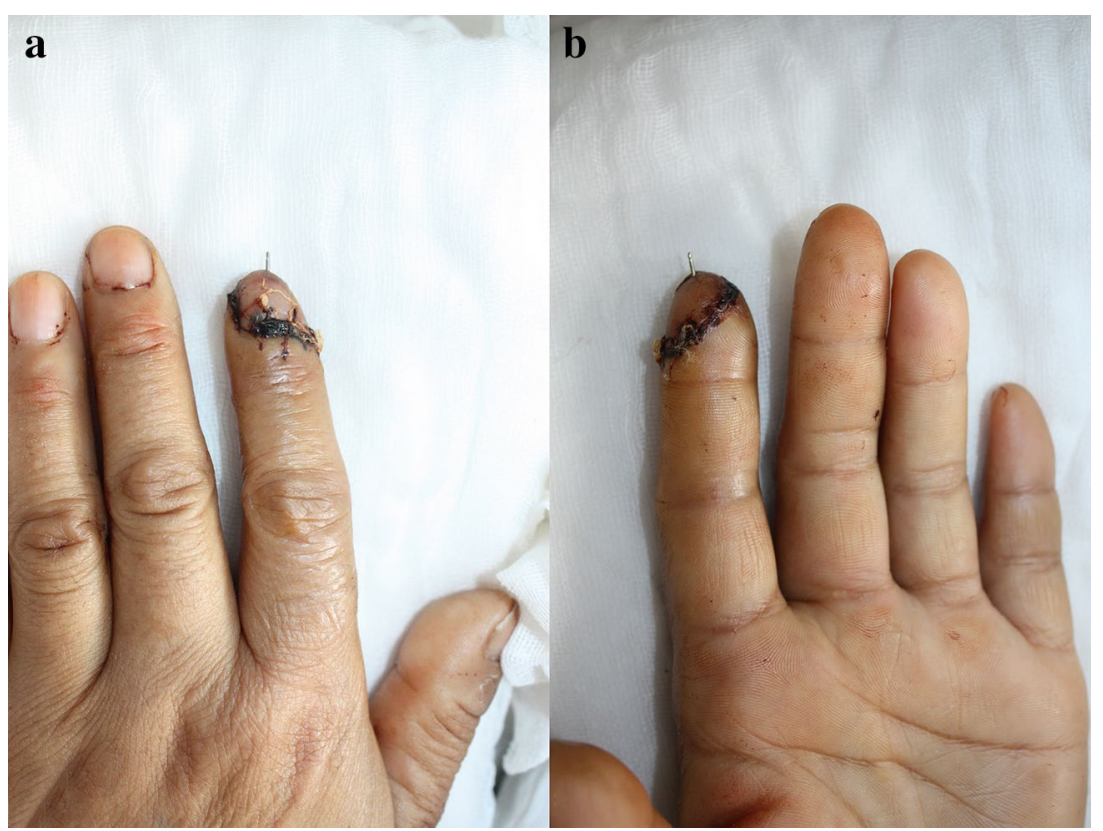

Fig. 4 Replanted fingertip at the time of discharge: dorsal view (a) and palmar view (b)

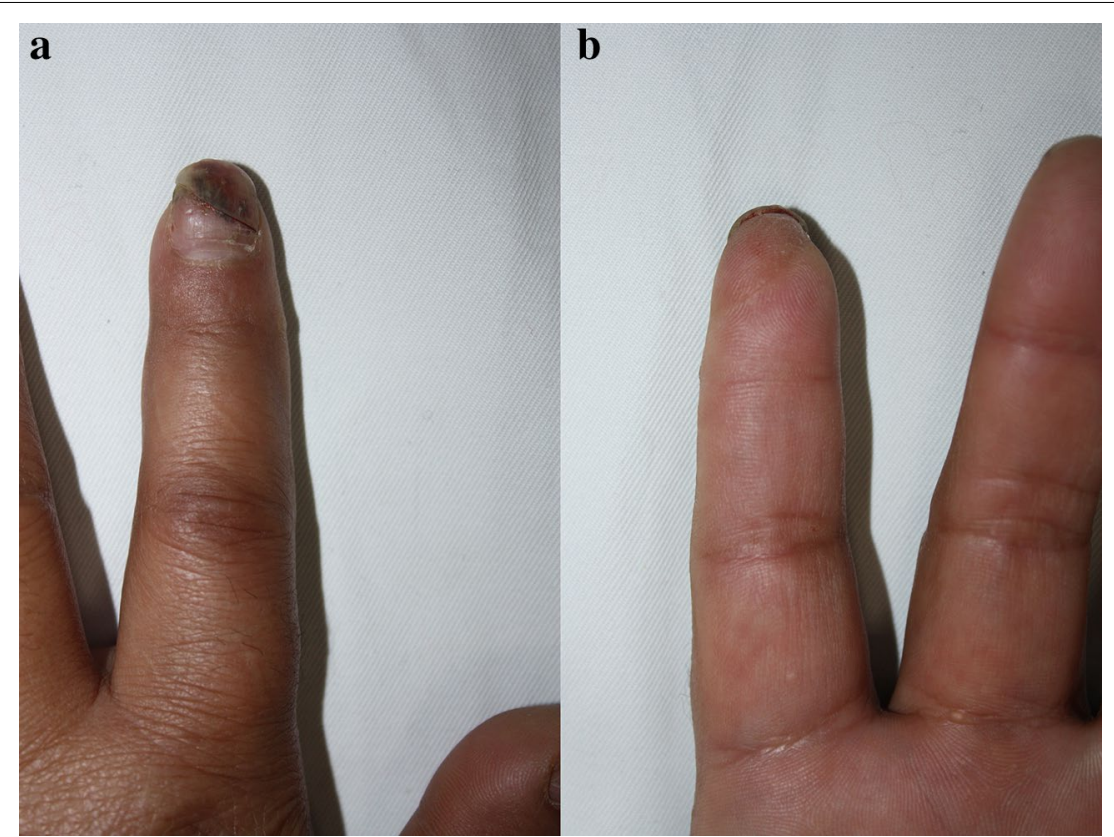

Fig. 5 Replanted fingertip at 12 months: dorsal view (a) and palmer view (b)

other methods of reconstruction should not be neglected (Wang et al. 2013). Moreover, the choice of technique should depend upon patients' overall physical and socioeconomic conditions, surgeon's microsurgical skills and availability of high facility centers.
In conclusion, artery-only fingertip replantation can provide satisfactory cosmetic and functional results. Adequate venous outflow can be obtained by allowing minimal external bleeding through wound gaps combined with topical and systemic heparin. 


\section{Authors' contributions}

AH has contributed substantially for the design of this work, data collection and analysis and has agreed to be accountable for all aspects of this work. SR has contributed substantially and equally to AH for the study design, data collection, interpretation and analysis along with manuscript preparation and copy-editing. JG has revised the work critically teaming with $\mathrm{HL}$ and WZ and approved the final version of this work to be published. $\mathrm{HL}$ along with WZ revised the work critically for important intellectual contents. WZ helped in data collection and analysis along with critical analysis for important intellectual contents. All authors agreed to be accountable for all aspects of this work in ensuring that questions related to accuracy or integrity of any part of the work are appropriately resolved. All authors read and approved the final manuscript.

\section{Author details}

${ }^{1}$ Department of Hand and Foot Surgery, Subei People's Hospital, Clinical Medical College of Yangzhou University, Yangzhou City 225001, Jiangsu Province, People's Republic of China. ${ }^{2}$ College of Medicine, Yangzhou University, 11th Huaihai Road, Yangzhou City 225009, Jiangsu Province, People's Republic of China.

\section{Acknowledgements}

N/A.

\section{Competing interests}

The authors declare that they have no competing interests.

\section{Funding}

This research received no specific grant from any funding agency in the public, commercial, or not-for-profit sectors.

Received: 9 April 2016 Accepted: 26 September 2016

Published online: 21 October 2016

\section{References}

Barbary S, Dap F, Dautel G (2013) Finger replantation: surgical technique and indications. J Hand Surg Eur 38:959-963

Buntic RF, Brooks D (2010) Standardized protocol for artery-only fingertip replantation. J Hand Surg Am 35:1491-1496

Chen HC, Tang YB, Noordhoff MS (1991) Bone marrow as a means of venous drainage for a microvascular osteocutaneous flap. Surgery 110:854-859

Chen KT, Chen YC, Mardini S, Wei FC (2005) Salvage of an avulsion amputated thumb at the interphalangeal joint level using afferentarteriovenous shunting. Br J Plast Surg 58:869-872

Chen YC, Chan FC, Hsu CC, Lin YT, Chen CT, Lin CH (2013) Fingertip replantation without venous anastomosis. Ann Plast Surg 70:284-288

Chen KK, Hsieh TY, Chang KP (2014) Tamai zone I fingertip replantation: is external bleeding obligatory for survival of artery anastomosis-only replanted digits? Microsurgery. 34:535-539

Erken HY, Takka S, Akmaz I (2013) Artery-only fingertip replantations using a controlled nailbed bleeding protocol. J Hand Surg Am. 38:2173-2179

Gordon L, Leitner DW, Buncke HJ, Alpert BS (1985) Partial nail plate removal after digital replantation as an alternative method of venous drainage. $J$ Hand Surg Am 10:360-364
Han SK, Chung HS, Kim WK (2002) The timing of neovascularization in fingertip replantation by external bleeding. Plast Reconstr Surg 110:1042-1046

Hasuo T, Nishi G, Tsuchiya D, Otsuka T (2009) Fingertip replantations: importance of venous anastomosis and the clinical results. Hand Surg 14:1-6

Hattori Y, Doi K, Ikeda K, Abe Y, Dhawan V (2003) Significance of venous anastomosis in fingertip replantation. Plast Reconstr Surg 111:1151-1158

Jeon BJ, Yang JW, Roh SY, Ki SH, Lee DC, Kim JS (2016) Lateral nail fold incision technique for venous anastomosis in fingertip replantation. Ann Plast Surg 76:67-71

Kim JS, Yang JW, Lee DC, Ki SH, Roh SY (2013) Challenges in fingertip replantation. Semin Plast Surg. 27:165-173

Kim SW, Han HH, Jung SN (2014) Use of the mechanical leech for successful zone I replantation. Sci World J 2014:105234

Matsuda M, Chikamatsu E, Shimizu Y (1993) Correlation between number of anastomosed vessels and survival rate in finger replantation. J Reconstr Microsurg 9:1-4

Nichter LS, Haines PC, Edgerton MT (1985) Successful replantation in the face of absent venous drainage: an experimental study. Plast Reconstr Surg 75:686-691

Ozcelik IB, Tuncer S, Purisa H et al (2008) Sensory outcome of fingertip replantations without nerve repair. Microsurgery 28:524-530

Peterson SL, Peterson EL, Wheatley MJ (2014) Management of fingertip amputations. J Hand Surg Am. 39:2093-2101

Sebastin SJ, Chung KC (2011) A systematic review of the outcomes of replantation of distal digital amputation. Plast Reconstr Surg 128:723-737

Streit L, Dvořák Z, Novák O, Stiborová S, Veselý J (2014) The use of medicinal leeches in fingertip replantation without venous anastomosis - case report of a 4-year-old patient. Acta Chir Plast 56:23-26

Tamai S (1982) Twenty years' experience of limb replantation: review of 293 upper extremity replants. J Hand Surg Am 7:549-556

Tanaka K, Kobayashi K, Murakami R, Tasaki Y, Fujii T, Mukae N (1998) Venous drainage through bone marrow after replantation: an experimental study. Br J Plast Surg 51:629-632

Venkatramani H, Sabapathy SR (2011) Fingertip replantation: technical considerations and outcome analysis of 24 consecutive fingertip replantations. Indian J Plast Surg. 44:237-245

Wang K, Sears ED, Shauver MJ, Chung KC (2013) A systematic review of outcomes of revision amputation treatment for fingertip amputations. Hand (NY). 8:139-145

Whitaker IS, Oboumarzouk O, Rozen WM, Naderi N, Balasubramanian SP, Azzopardi EA, Kon M (2012) The efficacy of medicinal leeches in plastic and reconstructive surgery: a systematic review of 277 reported clinical cases. Microsurgery 32:240-250

Yabe T, Muraoka M, Motomura H, Ozawa T (2001) Fingertip replantation using a single volar arteriovenous anastomosis and drainage with a transverse tip incision. J Hand Surg Am 26:1120-1124

Yabe T, Tsuda T, Hirose S, Ozawa T (2012) Treatment of fingertip amputation: comparison of results between microsurgical replantation and pocket principle. J Reconstr Microsurg 28:221-226

\section{Submit your manuscript to a SpringerOpen ${ }^{\circ}$ journal and benefit from:}

- Convenient online submission

- Rigorous peer review

Immediate publication on acceptance

- Open access: articles freely available online

- High visibility within the field

- Retaining the copyright to your article

Submit your next manuscript at springeropen.com 